The gold compound was heated in nitrogen, when it was found that an evolution of methyl sulphide begins at about $100^{\circ}$ and continues until the temperature approaches $200^{\circ}$. At higher temperature, pure gold is left as a residue.

The reaction leading to the formation of the gold compound resembles that by which the copper compound is produced, in that the auric chloride undergoes reduction, and the aurous chloride then unites with methyl sulphide. A trivalent gold atom appears to have its affinities satisfied partly by a chlorine atom, and partly by the sulphur atom of a methyl sulphide group.

It seems that in the compounds which have been here mentioned the metal is more firmly linked to the halogen than to the sulphur of the methyl sulphide, and that the part played by the methyl stilphide is somewhat like that of water in various hydrated salts. Ferrous chloride remains a ferrous compound no matter what may be the number of water molecules with which it combines.

Hydrated magnesium chloride is well known to lose hydrochloric acid on strong heating and in a somewhat analogous fashion some of the compounds of metallic halides with methy1 sulphide decompose on heating into metallic sulphide and methyl chloride.

A further study of compounds of alkyl sulphide with other metallic halides is in hand.

My acknowledgments are due to Mr. J. C. Fetterman, assistant in this laboratory, for his skill and careful attention to details in conducting many difficult and somewhat tedious analyses in connection with this work.

\title{
A NEW METHOD FOR THE ESTIMATION OF SOLUBLE NITROCELLULOSE IN GUNCOTTON AND SMOKELESS POWDER.
}

BY K. B. QUTNAN.

Recelved February 28,1901 .

\begin{abstract}
$A$ SHORT review of the methods now in use for the estimation $A$ of soluble nitrocellulose in guncotton and smokeless powder may be of interest to those who are not familiar with the subject under consideration. For this reason a brief description will be given here of the two methods most generally in use; namely, the (so-called) aliquot method, and the residual method which is
\end{abstract}


at present in use by the United States government as the official method.

The first-named method is essentially as follows: A weighed portion, about I gram, of the dried and finely divided sample of guncotton, or colloided powder is placed in a vessel of suitable shape, provided with a tight glass stopper, and is treated therein with $250 \mathrm{cc}$. of a mixture of ether-alcohol $2:$ I by volume. The contents of the vessel are thoroughly agitated by shaking until all the soluble nitrocellulose is in solution. An aliquot portion of this solution is now taken and placed in a small tared Erlenmeyer flask, of about $100 \mathrm{cc}$. capacity, and is evaporated to dryness therein at a temperature of $65.5^{\circ} \mathrm{C}$., the final drying being made at $100^{\circ} \mathrm{C}$. The Erlenmeyer flask is now cooled and weighed and the percentage of soluble nitrocellulose calculated from the weight of the colloid so obtained.

Although this method, as used in this laboratory, gives very accurate results, the opportunities for errors are many and various, and it requires much care to avoid them.

The second method, referred to as the residual method, gives very unsatisfactory results. It is essentially as follows (taken verbatim from the United States government syllabus): "About I. 5 grams of the finely divided, dry sample are treated in a covered beaker or other suitable vessel, with $250 \mathrm{cc}$. of a mixture of I volume absolute alcohol, C. P., and 2 volumes of strongest ether, C. P., with frequent stirring, for not less than two hours. (Four hours are frequently necessary for complete solution.) The vessel is kept covered to prevent loss by evaporation. The residue is allowed to settle and the supernatant liquid decanted through an asbestos filter, made from well purified asbestos fiber. The filter is placed in the neck of a flask or otherwise protected to avoid loss of solvent by evaporation during filtration.

"The residue in the flask is then treated with a further quantity of $200 \mathrm{cc}$. of ether-alcohol mixture, and again thoroughly stirred until extraction is complete; and the whole mass is then settled. The clear liquid may be decanted, and the remainder filtered through the asbestos fiber and well washed by successive portions of ether-alcohol. The filter is then partially dried at $40^{\circ} \mathrm{C}$., and the drying completed by exposure to a temperature of $100^{\circ} \mathrm{C}$. for two hours. The loss (minus any volatile matter, if present) represents soluble nitrocellulose." 
The main difficulty encountered in the operation of this method is the filtration of the thick colloid formed by the guncotton and ether-alcohol. It is practically impossible to effect the passage of the thick colloid through an asbestos filter without the aid of great pressure, and a large expenditure of valuable time, for the filtration is extremely slow even under the most favorable conditions. Another strong objection to the method lies in the fact that it usually requires four or five days for the completion of an analysis by this method, which renders it practically valueless for manufacturers.

The above outlined syllabi are merely intended to convey a general idea of the methods in use, and to show in a general way the objections to each method. It was to overcome these objectionable features in the methods above described that the following method was devised by the writer, which may be termed the "centrifugal method."

As far as the author is aware, the theory of centrifugal sedimentation has never as yet been applied to this particular subject. The application of this theory to the analysis of smokeless powder is as follows:

APPARATUS.

The apparatus consists of a centrifugal machine, essentially as
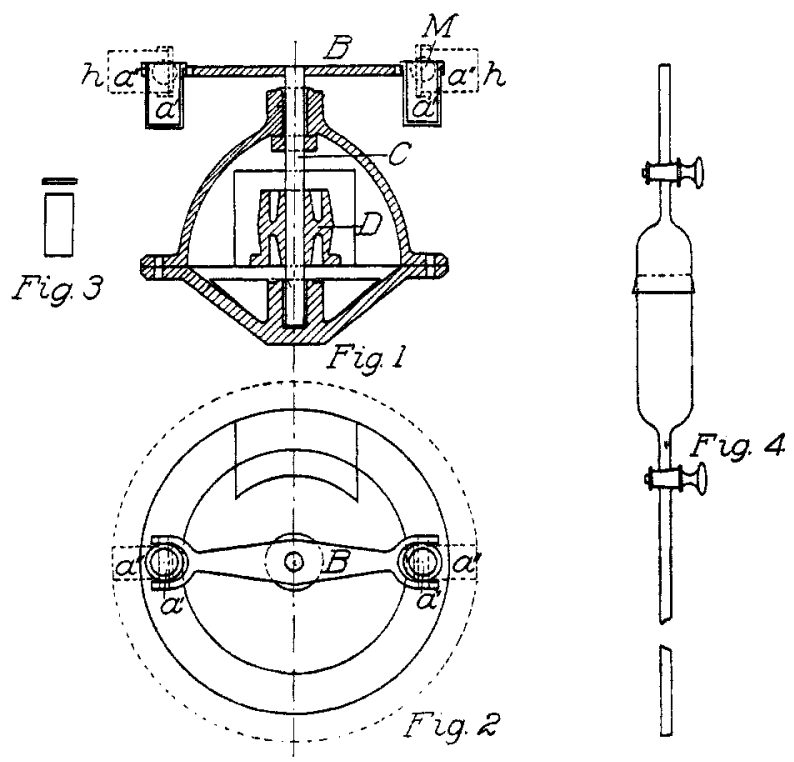
per attached sketch. The vertical driving shaft $(C)$ carries at its upper extremity a horizontal arm $(B)$, at its lower extremity the driving pulley $(D)$. To each end of the horizontal arm $(B)$ are attached adjustable cups $\left(a^{\prime} a^{\prime}\right)$ arranged on side pivots, so that they may assume a horizontal position when in motion.

\begin{tabular}{|c|c|c|c|c|c|c|}
\hline Driving shaft $(C) \ldots$ & $\begin{array}{l}\text { Length. } \\
\text { I6 } 6 \frac{5}{8} "\end{array}$ & 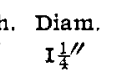 & $\begin{array}{l}\text { width. } \\
\ldots \ldots\end{array}$ & $\begin{array}{l}\text { Depth. } \\
\ldots \ldots . .\end{array}$ & $\begin{array}{l}\text { Thick. } \\
\text {.. }\end{array}$ & $\begin{array}{c}\text { Material. } \\
\text { Machine steel }\end{array}$ \\
\hline Horizontal arm $(B)$ & $17^{\prime \prime}$ & 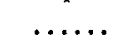 & $\left\{\begin{array}{l}\max 3 \frac{1}{4} \prime \prime \\
\min 1 \frac{1}{4}\end{array}\right.$ & $\cdots$ & $\frac{1}{2} \prime \prime$ & Forged steel \\
\hline 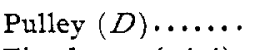 & $\cdots$ & $4 \frac{11}{4}$ & $5^{\prime \prime}$ & & . & Cast iron \\
\hline aps $\left(a^{\prime} a^{\prime}\right)$. & . & side-2" & $\cdots$ & inside $-4^{\prime \prime}$ & .' & Steel \\
\hline earing $(M) \ldots$ & .. & $\frac{1}{2} "$ & $\frac{1}{2} "$ & $\ldots \ldots$ & .. & Steel \\
\hline
\end{tabular}

Revolutions per minute of $\operatorname{arm}(B) \ldots \ldots \ldots \ldots \ldots \ldots \ldots, 2000$

Total centrifugal force at $(h) \ldots \ldots \ldots \ldots \ldots \ldots \ldots \ldots \ldots, 450$ 1b. (about)

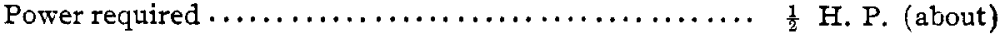

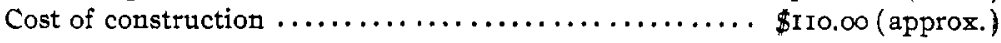

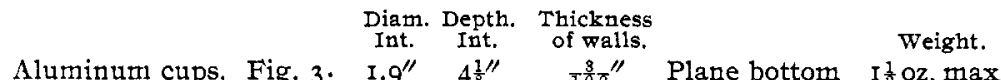

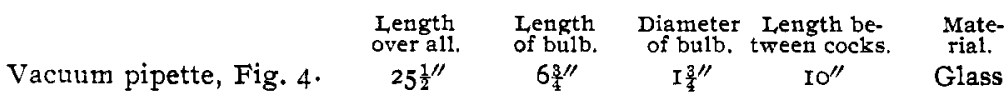

OPERATION.

About I gram of the finely divided (dry) sample of guncotton or smokeless powder, which is to be analyzed, is weighed on a watch-glass and is transferred to the aluminum vessel (Fig. 3) which has previously been thoroughly cleansed and dried. (Or the sample may be weighed into the aluminum vessel direct, if so desired.) To this is added $50 \mathrm{cc}$. of alcohol and the sample is thoroughly stirred to bring it into suspension. roo cc. of ether are now added to the mixture in the cup, and the whole is then stirred for several minutes. ${ }^{1}$ After removing the stirring rod, the aluminum vessel containing the solution is placed in one of the cups $\left(a^{\prime} a^{\prime}\right)$ of the centrifugal machine (Fig. I) and is covered by a loosely fitting aluminum cap. In the other cup of the centrifugal machine is placed a second aluminum vessel, containing a second sample which has been treated in the above described manner. (In this way two determinations may be carried on at the same time.) The centrifugal machine is now started gradually and allowed to remain running at top speed for ten to twelve minutes. This has been found to be a sufficient length of time for the complete sedimentation of all in-.

1 See last paragraph as to solvents. 
soluble matter in the solution. The machine is now stopped gradually, and the aluminum vessels are removed from the cups $\left(a^{\prime} a^{\prime}\right)$ and placed in a convenient position before the operator. All insoluble matter will now be found in the bottom of the aluminum vessels, and the perfectly clear supernatant liquid may be drawn off to within a quarter of an inch of the bottom of the aluminum vessels. This is done by means of the vacuum pipette shown in Fig. 4. The air in the bulb of this pipette is exhausted by means of an air-pump before use. The advantage gained by using the vacuum pipette is very easily seen, for when the lower end of the pipette is submerged in the clear liquid in the aluminum vessel and the lower stop-cock is opened, the clear solution from the vessel at once rises in the tube and passes into the bulb of the pipette. By lowering the pipette from time to time, nearly all the supernatant liquid may be drawn up into the bulb without disturbing the precipitate in the bottom of the vessel. If, however, the precipitate is disturbed it will at once be noticed as it rises in the tube clouding the clear liquid. If this should take place, the lower valve is immediately closed, thus preventing the access of the insoluble matter to the clear liquid in the bulb. The upper valve is now opened, thus releasing the tension in the bulb, so that when the lower valve is cautiously opened and a few drops of the liquid are allowed to run out of the tube and into the aluminum ressel, they carry with them all suspended matter which may have been drawn into the tube. In this way all opportunity for loss of insoluble matter is avoided. There now remains in the aluminum vessels about 10 or $15 \mathrm{cc}$. of colloid solution and a film of insoluble matter on the bottom of the vessels. Stir this insoluble matter up from the bottom of the vessel with a glass stirring rod, wash the rod thoroughly by means of a washbottle filled with pure ether-alcohol, and at the same time rinse down the sides of the aluminum ressels with the ether-alcohol from the wash-bottle. Now add about 50 to $75 \mathrm{cc}$. of fresh etheralcohol to the mixture in the vessels, stir it up, place in the centrifugal, and again proceed in the manner already described. This operation should be repeated several times until all traces of soluble matter have been removed. Seven or eight washings usually suffice to remove entirely all soluble matter. Samples containing a high percentage of insoluble matter may require trelve or more washings to complete extraction. 
After the extraction has been completed the insoluble matter is transferred to a weighed Gooch crucible provided with the usual asbestos pad, is dried therein at $100^{\circ} \mathrm{C}$, and weighed. If preferred, the insoluble matter may be dried and weighed directly in the aluminum vessel in which the extraction was performed. The only objection to drying and weighing directly in the aluminum vessel is that this vessel cannot be ignited.

The whole time required for an analysis by this method, exclusive of the time required for drying, is from one to two hours. The average time which has been found uecessary to complete an analysis is about one and one-quarter hours, for it will readily be seen that in each successive extraction, the viscosity of the solution decreases, and consequently the sedimentation is much more rapid toward the end of the analysis than it was in the beginning. For instance, the first solution obtained is a thick colloid and requires about ten or twelve minutes in the centrifugal for sedimentation, but with the second solution, about eight minutes in the machine will suffice.

This method is equally applicable to the estimation of acetonesoluble nitrocellulose, the operation being the same as in the case of the ether-alcohol extraction already described.

The results obtained by this method have been highly satisfactory both for accuracy and rapidity.

The following analyses were made on a sample of nitrocellulose containing a known amount of insoluble matter:

No. of analysis. Insoluble matter found. Insoluble matter required.

$\begin{array}{ccc}2664 & 0.54 & 0.69 \\ 2665 & 0.50 & \text { (Determined by aliquot method.) } \\ 2666 & 0.59 & \\ 2667 & 0.53 & \end{array}$

These results may be improved upon by further experience with the method.

In laboratories where power is not available, the form of the centrifugal machine herein described may be modified, and provided with gear so as to admit of its being run by hand. The use of power is, of course, preferable. This syllabus is based upon the results obtained with a machine of the dimensions herein described.

In order to make the laboratory analysis analogous to the process of manufacture, the solvents used should be of the same 
strength as those ordinarily used in manufacture. Care must be taken, however, that the solvents are free from all matter not volatile at $100^{\circ} \mathrm{C}$.

[CONTRIbUtions from the CHEMICAL Laboratory OF CASE School oF APPLIED SCIHNCE, No. 39.]

\section{COMPOSITION OF TEXAS PETROLEUM.}

by Charles F. MaberY.

Received Fehruary 9, 5901

INDICATIONS of the presence of petroleum in Texas in several sections have been observed during the last thirty years, and many attempts have been made to obtain oil in sufficient quantities for the preparation of commercial products. But it is only within the last six years that oil has been found in sufficient amounts to encourage further development. The principal yield has been in the counties of Navarro, Bexar, Nacagdoches, and Hardin, and the chief supply has come from the Corsicana field in Navarro County. In the early development of the Corsicana field a specimen of the oil was briefly examined by Thiele, ${ }^{1}$ who gave its specific gravity as 0.8296 , and the proportions in temperatures Fahrenheit in which it distilled. The resemblance of this oil to Pennsylvania and to Ohio petroleum alluded to by the author seems to be scarcely supported by the meager examination.

Corsicana oil was later examined by Richardson, ${ }^{2}$ who obtained percentages of carbon and hydrogen in the distillate $100^{\circ}-150^{\circ}$ at $25 \mathrm{~mm}$., corresponding to the series $\mathrm{C}_{n} \mathrm{H}_{2 n}$.

Another important section of the Texas oil field has recently been developed in Jefferson County, and it has suddenly become famous by the discovery of a large pool, under high pressure, that has furnished the phenomenal supply in the Iucas well. The surface indications in this section, in the vicinity of Sabine Pass, were such that this pool narrowly escaped previous Aiscovery by other prospectors. Oil has been obtained in smaller amounts for some time in this county, and the composition of one specimen was ascertained by Mabery and Buck. ${ }^{3}$ This oil was found to consist mainly of the series of hydrocarbons represented by the general symbols $\mathrm{C}_{n} \mathrm{H}_{2 \mathrm{n}-2}$ and $\mathrm{C}_{\mathrm{n}} \mathrm{H}_{2 n-4}$. It was an extremely heavy petroleum, specific gravity 0.9500 . Scarcely any distilled below

1 Am. Chem. J., 22, 489.

2 J. Soc. Chem. Ind., February, 1900.

3 This Journa1, 22, 553 . 